\title{
LOS DERECHOS SEXUALES Y REPRODUCTIVOS EN LA JURISPRUDENCIA DE LA CORTE INTERAMERICANA DE DERECHOS HUMANOS*
}

\section{César Landa}

Ex Presidente del Tribunal Constitucional. Profesor de Derecho Constitucional en la Pontificia Universidad Católica del Perú (Lima) y en la Universidad Nacional Mayor de San Marcos. E-mail: <clanda@pucp.edu.pe>.

\begin{abstract}
Resumen: La Corte Interamericana de Derechos Humanos (Corte IDH) en la última década ha dejado de resolver exclusivamente casos vinculados a derechos humanos clásicos para comenzar a fallar también sobre demandas por novísimos derechos humanos relativos tanto a los derechos sexuales y reproductivos, como a la orientación sexual e identidad de género. La Corte ha realizado una interpretación de los derechos fundamentales orientada a eliminar los patrones históricos tradicionales que consideran a la mujer en una situación de desventaja frente al varón. En otro sentido, también es relevante que la Corte IDH haya incorporado en su reflexión un concepto de familia en sentido amplio, en el que se privilegian los lazos y vínculos afectivos, antes que el modelo patriarcal de familia matrimonial propio de sociedades tradicionales pre modernas. La Corte IDH ha incorporado conceptos como el de derecho a la discriminación indirecta, ya que ello refleja un análisis material del concepto de igualdad. En el mismo sentido, es importante que haya definido el concepto de los derechos sexuales y reproductivos sin discriminación particularmente indirecta, y, que haya diferenciado los tres supuestos: discapacidad, género y condiciones socioeconómicas, en los que se configura un trato desigual desproporcionado.
\end{abstract}

Palabras-chave: Derechos sexuales. Derechos reproductivos. Corte Interamericana de Derecho Humanos.

Sumario: 1 Presentación - 2 Libertad sexual: Atala Riffo y niñas vs. Chile - $\mathbf{3}$ Reproducción sexual asistida: Artavia Murillo y otros vs. Costa Rica - 4 Conclusiones - Bibliografía consultada

\section{Presentación}

El proceso de modernización democrática de las sociedades tradicionales de América Latina, iniciado en las décadas finales del siglo XX, ha traído como consecuencia la revalorización de la mujer, como un sujeto jurídico de especial protección nacional e internacional; dada la histórica subordinación y discriminación

* Ponencia presentada al Seminario Internacional "Diálogos Judiciales en el Sistema Interamericano de Garantía de los Derechos Humanos”. Universitat Pompeu Fabra. Barcelona, del 25 al 27 de febrero de 2015. 
social y económica a la cual ha estado sometida, por el modelo patriarcal de la sociedad y del Estado. Así, las normas nacionales han ido evolucionando progresivamente de cara al reconocimiento para la mujer de derechos de igualdad de oportunidades y de trato que al varón sin discriminación alguna; sin embargo, paradójicamente a estos avances en las normas constitucionales y/o legales, se viene produciendo nuevos desafíos al rol de la mujer incluso en las sociedades con altos niveles educativos para la región, como Chile y Costa Rica.

La vis expansiva de la igualdad ha sido posible gracias a la transformación del concepto jurídico de la igualdad en la ley, hacia una idea dinámica de igualdad en la aplicación en la ley, y, sobretodo, a la no discriminación por razones de sexo, raza, idioma, entre otras, particularmente de grupos sociales históricamente vulnerables -mujeres, indígenas, niños, extranjeros, discapacitados, etc.-. Así, en el caso de las mujeres ha ido quedando atrás el uso de la diferencia sexual como fundamento jurídico para que mujeres y hombres tengan por "naturaleza" roles y destinos diferentes. ${ }^{1}$

Por su parte, la Corte Interamericana de Derechos Humanos (Corte IDH) en la última década ha dejado de resolver exclusivamente casos vinculados a derechos humanos clásicos como los relativos a la protección del derecho a la vida, integridad o libertad personal, para comenzar a fallar también sobre demandas por derechos de libertad de expresión, nacionalidad, propiedad, debido proceso, vida privada, así como, sobre novísimos derechos humanos relativos tanto a los derechos sexuales y reproductivos, como a la orientación sexual e identidad de género, los cuales están íntimamente vinculados al derecho a la vida privada personal y familiar, que proteje la Convención Americana sobre Derechos Humanos (CADH).

Este proceso pone en evidencia que la categoría de derechos humanos en principio es un concepto jurídico abierto al cual se le llena de nuevos contenidos, en función de las nuevas demandas de las sociedades latinoamericanas. Por cuanto, la satisfacción de las demandas sociales básicas de acuerdo a las necesidades del tiempo y el lugar es un deber y una obligación estatal, que de no satisfacerlas le corresponde al Sistema Interamericano de Derechos Humanos, en función a las peticiones de sus ciudadanos ante la Comisión Interamericana de Derechos Humanos (Comisión IDH) y, en caso de econtrar una solución amistosa, de formular una demanda ante la Corte IDH, para que se pronuncie a través de un proceso judicial que termine con una sentencia.

Por su parte, la Corte IDH con la renovación periódica de sus jueces ha ido evolucionando su forma de interpretar la Convención Americana, de una aplicación literal y formal hacia una interpretación dinámica y expansiva en la tutela de

PAUTASSI, Laura (2012): pp. 715-718. 
los derechos demandados; lo cual no hubiera sido posible sin el proceso de fortalecimiento del modelo democrático-constitucional en los países de la región americana. Esto ha puesto de manifiesto que valores constitucionales como el reconocimiento del pluralismo jurídico y la tolerancia social ponga al debate público el reconocimiento de nuevos derechos humanos, como son la reproducción sexual asistida y la orientación sexual.

Al respecto, si bien la Comisión IDH ha recibido algunos casos relativos a la discriminación por orientación sexual, estos no llegaron a la Corte IDH, sino hasta el caso de Karen Atala Riffo y niñas contra Chile (2012) y en materia de derechos sexuales y reproductivos el caso de Artavia Murillo y otros contra Costa Rica (2012), los cuales son materia de la presente comunicación.

\section{La libertad sexual: Atala Riffo y niñas vs. Chile}

El 24 de febrero de 2012, la Corte Interamericana emitió una sentencia respecto al caso de Karen Atala Riffo contra el Estado de Chile. En el año 2003, Atala fue demandada por su ex esposo por la tuición de sus hijas menores de edad, debido a que ellas se encontraban conviviendo con su madre y su pareja del mismo sexo. Las sentencias de primera y segunda instancia reconocieron el derecho de Atala, sosteniendo que no había pruebas que acreditara que no podría ejercer la maternidad de manera responsable debido a su orientación sexual.

Sin embargo, mediante un recurso extraordinario, la Corte Suprema de Chile revocó los fallos anteriores y concedió la tuición definitiva al padre de las niñas, sosteniendo, entre otros argumentos que Atala: (i) "ha antepuesto sus propios intereses, postergando los de sus hijas, especialmente al iniciar una convivencia con su pareja homosexual"; (ii) que hubo una confusión de roles sexuales en las niñas producto de la carencia en el hogar de un padre de sexo masculino, lo cual supondría un riesgo para el desarrollo integral de las menores; y (iii) que las menores podrían sufrir discriminación por parte de quienes conforman su entorno, tales como el vecindario o la escuela. ${ }^{2}$

En 2004, Karen Atala Riffo presentó una petición contra el Estado de Chile ante la Comisión Interamericana, la cual presentó la demanda el 17 de septiembre de 2010. En 2012, la Corte Interamericana la declaró fundada ante la Corte Interamericana en la medida que la Corte Suprema de Chile vulneró los derechos a la igualdad y no discriminación, el derecho a la vida privada, el derecho a la honra y a la dignidad), así como, la protección a la familia, consagrados en la Convención

CORTE IDH. Caso Atala Riffo y Niñas Vs. Chile, párr. 97. 
Americana sobre Derechos Humanos. También es del caso señalar que se tuteló la libertad sexual debido a que la Corte Suprema de Chile no respetó la orientación sexual de la demandante, afectando su dignidad y el derecho al libre desarrollo de la personalidad.

Si bien la Corte Interamericana no se pronunció directamente sobre la libertad sexual base la cual se fundamenta la orientación sexual, en tanto esta es una de las manifestaciones de los derechos a la libertad sexual, si lo hace indirectamente a través de la extensión del principio de libertad, igualdad y no discriminación por orientación e identidad de género.

Así, por un lado, la Asamblea General de las Naciones Unidas adoptó el 22 de diciembre de 2008, la "Declaración sobre derechos humanos, orientación sexual e identidad de género", afirmando el principio de no discriminación, independientemente de la orientación sexual o identidad de género. Asimismo, en el Sistema Interamericano de Derechos Humanos, la Asamblea General de la Organización de Estados Americanos, ha aprobado desde el año 2008, cuatro resoluciones sobre la protección de las personas contra tratos discriminatorios basados en su orientación sexual e identidad dd género. ${ }^{3}$

Por otro lado, en el XIII Congreso Mundial de Sexología celebrado en Valencia en 1997 se aprobó la Declaración Universal de Derechos Sexuales, reconociendo los siguientes derechos fundamentales: (i) a la libertad sexual, (ii) a la autonomía a la integridad y a la seguridad sexual del cuerpo, (iii) a la privacidad sexual, (iv) a la igualdad sexual, (v) al placer sexual, (vi) a la expresión sexual emocional, (vii) a la libre asociación sexual, (viii) a la toma de decisiones reproductivas libres y responsables, (ix) a la información sexual basada en el conocimiento científico, (x) a la educación sexual integral y (xi) a la atención de la salud sexual.

En particular, la Declaración de Derechos Sexuales define el contenido del derecho fundamental a la libertad sexual como aquel que "abarca la posibilidad de la plena expresión del potencial sexual de los individuos. Sin embargo, esto excluye toda forma de coerción, explotación y abuso sexuales en cualquier tiempo y situación de vida".

De modo que, se puede colegir de los tratados y la doctrina internacional que la libertad sexual es el derecho que permite a las personas expresar su propia sexualidad sin padecer discriminación alguna por motivo de orientación sexual o identidad de género. Tal es el caso de Atala Riffo y su pareja que al formar un hogar con las niñas de la primera, son suceptibles de la protección del Estado, de acuerdo a los estándares internacionales de derechos humanos. En consecuencia, la libertad de la orientación sexual constituiría un derecho fundamental de la persona

CORTE IDH. Caso Atala Riffo y Niñas Vs. Chile, párr. 87. 
que así lo decida, pues se basa en el principio de la dignidad humana y en otros principios como el de la igualdad de trato y de oportunidades sin discriminación alguna, que también gozan de protección constitucional en los ordenamientos latinoamericanos.

\subsection{Dignidad y libertad sexual}

Si bien la dignidad no es mencionada específicamente como un derecho afectado a Karen Atala en el caso concreto, al ser el principio que fundamenta todo el ordenamiento jurídico constitucional y constituye la base filosófica de los derechos humanos, consideramos que debió ser considerada para comprender a mayor profundidad la sentencia dictada por la Corte Interamericana y su aproximación práctica y teórica al derecho a la libertad sexual.

Asi, por ejemplo la Suprema Corte de Justicia de la Nación de México ha señalado que:

de la dignidad humana [...] deriva, entre otros, el libre desarrollo de la personalidad, es decir, el derecho de todo individuo a elegir, en forma libre y autónoma, cómo vivir su vida, lo que comprende, entre otras expresiones, [...] su libre opción sexual. [L]a orientación sexual de una persona, como parte de su identidad personal, [es] un elemento relevante en el proyecto de vida que tenga y que, como cualquier persona, incluye el deseo de tener una vida en común con otra persona de igual o distinto. ${ }^{4}$

No obstante, el concepto jurídico de la dignidad humana se muestra problemático en la doctrina; debido a que se ha cuestionado acerca de su naturaleza, es decir, si se trata de un auténtico derecho fundamental o por el contrario es solo un principio que no resulta exigible. Existe consenso en cuanto a la importancia de la dignidad como un principio rector que potencializa los derechos fundamentales, ${ }^{5}$ enriqueciéndolos con nuevos significados cuando se vinculan con el goce y ejercicio de los derechos y libertades, y que orienta la actividad normativa y jurisprudencial, como puede ser el caso de la libertad sexual de las personas.

Sin embargo, debe reconocerse también que la dignidad no solo es un principio de todo ordenamiento constitucional y democrático, sino que también es un derecho fundamental que como tal resulta exigible en relación a los derechos

CORTE INTERAMERICANA DE DERECHOS HUMANOS. Sentencia Atala Riffo vs. Chile. Párrafo 137.

LANDA, César (2002): pp. 109-138. 
y libertades fundamentales. Así, al ser exigibles pueden los individuos reforzar la demanda de la intervención de los órganos jurisdiccionales para su protección. ${ }^{6}$

Desde tal perspectiva, los Estados latinoamericanos no tienen solamente el deber de interpretar la libertad sexual desde la perspectiva de la dignidad humana, sino también de proteger la dignidad sexual de las personas como un derecho en sí mismo. Así, la dignidad en materia de libertad sexual tendría eficacia tanto horizontal ante los particulares, es decir, en la voluntariedad o consentimiento de las relaciones sexuales entre las personas, como eficacia vertical frente a las autoridades, en cuanto es oponible a intervenciones de autoridades del Estado o de poderes privados. La dignidad, entonces, no es solo el principio sobre el cual se asienta el Estado democrático constitucional; sino que también es el derecho humano que fundamenta la validez y exigencia de la libertad sexual.

La Corte Interamericana de Derechos Humanos ha señalado incidentalmente que el respeto a la dignidad se da de manera independiente de la condición existencial de la persona, es decir, "de la situación y de las circunstancias en que se encuentre", ${ }^{7}$ por tanto, es completamente inherente al ser humano por su condición de tal. Asimismo, la dignidad goza de un efecto de irradiación a los demás derechos fundamentales, de forma directa o también indirecta.

En consecuencia, la dignidad en relación a la libertad sexual puede interpretarse en dos sentidos. En un sentido positivo, puede decirse que la dignidad supone un deber de promoción de la máxima realización posible del libre desarrollo de la persona humana. Por otro lado, en un sentido negativo, se vuelve una prohibición de instrumentalización de la persona, es decir, que no se la convierta, más aún si es vulnerable, en simple objeto de la acción o coacción de particulares o del Estado. ${ }^{8}$ Ambas connotaciones de la dignidad humana hacen referencia al principio ontológico referido al ser humano como un fin en sí mismo. ${ }^{9}$

No obstante, debe reconocerse que la dignidad sexual debe tener límites, los cuales pueden ser internos, “que se basan en la autonomía y libertad personal, pero también en la autoestima valorativa que una persona tiene de sí misma, lo cual genera no sólo derechos sino también deberes de prevención y protección de su propia dignidad y con mayor responsabilidad de quienes están bajo su cuidado o responsabilidad", ${ }^{10} 0$; externos, que se definen en la contraposición práctica que

\footnotetext{
TRIBUNAL CONSTITUCIONAL DEL PERÚ. Expediente 02273-2005-PHC/TC, FJ. 10. CORTE IDH. Caso La Cantuta vs. Perú, párr. 30.

BENDA, Ernst (1996): p. 125.

La Corte IDH cita a manera de ejemplo “la célebre concepción kantiana de la persona humana como un fin en sí misma. Esto es inevitable, por cuanto refleja el proceso de maduración y refinamiento del propio espíritu humano, que torna posibles los avances en la propia condición humana". CORTE IDH. Caso La Cantuta vs. Perú, párr. 30.

10 LANDA, César (2009): p. 4.
} 
en ciertos casos pueda darse de la dignidad sexual con los derechos fundamentales de otras personas, por ejemplo, menores de edad que se encuentren bajo su protección o tutela.

Tal es el caso de las hijas de Atala Riffo que al estar viviendo con su madre y la pareja de esta del mismo sexo, se configura la necesidad de proteger la dignidad en un alto grado para cada una de los miembros de la familia constituida, pero particularmente para las menores, en relación a la comunidad y a las autoridades. Por cuanto, dicha unión lésbica de facto se basa en el reconocimiento de derechos, pero también de deberes, sobretodo con la educación y cuidado integral -físico, psiquico y moral- de las menores; así como, en el respeto de la dignidad familiar en relación con la comunidad, la escuela, y, en general la sociedad y las autoridades. ${ }^{11}$

\subsection{Derecho a la igualdad y no discriminación por orientación sexual}

La igualdad es un derecho fundamental que puede reconocerse en tres dimensiones: en la ley, es decir, una obligación del legislador frente a los particulares; en la aplicación de la ley, un deber del juez y el árbitro respecto a los individuos; y en el trato, que constituye un principio que debe regir los comportamientos entre particulares. Si bien, "el valor o bien jurídico protegido por el principio de igualdad ante la ley es la idéntica dignidad de todos los miembros del cuerpo político", ${ }^{12}$ al ser la dignidad humana su fundamento, el derecho a la igualdad "[rechaza] toda creación o aplicación del Derecho que trate a algunos miembros de la comunidad como ciudadanos de segunda clase". ${ }^{13}$

En consecuencia, el principio de igualdad se complementa con el de no discriminación; dado que se vulnera cuando existe un trato distinto a un grupo en comparación con otros, a pesar de que ambos grupos no tengan una diferencia razonable que justifique dicha variación en los tratos. ${ }^{14}$ No obstante, debe precisarse que este derecho no supone un trato exactamente idéntico hacia todos los individuos, pero tampoco permite que se den tratos diferenciados de manera injustificada, como es el caso de la opción u orientación sexual, derivada de la libertad sexual.

11 GIL, Andrés, María FAMA Y Marisa HERRERA. (2012): pp. 158-170.

12 DIEZ-PICAZO, Luis (2005): p 191.

13 REY, Fernando (2011): p. 4

14 BERNAL PULIDO, Carlos (s/fecha): pp. 14-15. 
En el ámbito del Sistema Interamericano, la Convención Americana sobre Derechos Humanos establece en dos de sus artículos la igualdad de todas las personas en cuanto al trato del Estado:

Artículo 1. Obligación de Respetar los Derechos

1. Los Estados Partes en esta Convención se comprometen a respetar los derechos y libertades reconocidos en ella y a garantizar su libre y pleno ejercicio a toda persona que esté sujeta a su jurisdicción, sin discriminación alguna por motivos de raza, color, sexo, idioma, religión, opiniones políticas o de cualquier otra índole, origen nacional o social, posición económica, nacimiento o cualquier otra condición social. (...)

Artículo 24. Igualdad ante la Ley

Todas las personas son iguales ante la ley. En consecuencia, tienen derecho, sin discriminación, a igual protección de la ley (...).

Ahora bien, el caso en mención es relevante porque refleja la incorporación de una perspectiva en la que la igualdad se vincula con la política del reconocimiento de la diversidad social, que desde la lógica de este principio o derecho, "exige medidas para luchar contra la injusticia de los prejuicios culturales y los patrones de discriminación a través de la transformación cultural y la adopción de una política de reconocimiento". ${ }^{15}$

En efecto, a juicio de la Corte IDH, la orientación sexual es un motivo de discriminación prohibido por el artículo 1.1 de la Convención. ${ }^{16}$ De hecho, el criterio de la orientación sexual no figura como uno de los supuestos previstos en dicho dispositivo, sin embargo, la Corte construye argumentos razonables que justifican esta incorporación. En primer lugar, la Corte señala que el artículo 1.1 no establece un listado taxativo sobre los criterios prohibidos sino enunciativos.

En esa misma lógica, ha recurrido a la jurisprudencia del Tribunal Europeo de Derechos Humanos, en concreto al caso Salgueiro da Silva Mouta vs. Portugal, para señalar que la orientación sexual es un concepto que se encuentra cubierto

15 PIOVESAN, Flavia (s/fecha): pp. 491-493.

16 Los criterios específicos en virtud de los cuales está prohibido discriminar, según el artículo 1.1 de la Convención Americana, no son un listado taxativo o limitativo sino meramente enunciativo. Por el contrario, la redacción de dicho artículo deja abiertos los criterios con la inclusión del término "otra condición social” para incorporar así a otras categorías que no hubiesen sido explícitamente indicadas. La expresión "cualquier otra condición social" del artículo 1.1. de la Convención debe ser interpretada por la Corte, en consecuencia, en la perspectiva de la opción más favorable a la persona y de la evolución de los derechos fundamentales en el derecho internacional contemporáneo. CORTE IDH. Caso Atala Riffo y Niñas Vs. Chile. Párr. 85. 
dentro de los motivos prohibidos; y en la misma lógica, se ha hecho mención a la práctica del Comité del Pacto de Derechos Civiles y Políticos que ha afirmado que la referencia a la categoría "sexo" incluiría la orientación sexual de las personas. De ese modo, encuentra en el diálogo jurisprudencial o cuasi jurisprudencial un respaldo en la tutela de los nuevos derechos humanos.

Asimismo, la Corte IDH respondió al argumento planteado por el gobierno chileno que planteaba que la categoría sospechosa de la orientación sexual no era un criterio sobre el que existiera consenso al momento en que la Corte Suprema de Chile emitiera el fallo por el cual se otorgara la custodia de las hijas de Atala al padre de las mismas. En concreto, señaló que:

la presunta falta de un consenso al interior de algunos países sobre el respeto pleno por los derechos de las minorías sexuales no puede ser considerada como un argumento válido para negarles o restringirles sus derechos humanos o para perpetuar y reproducir la discriminación histórica y estructural que estas minorías han sufrido.

\section{Test de igualdad en el caso Atala Riffo}

En principio, la Corte IDH no ha realizado propiamente un test de proporcionalidad en torno a la decisión del Estado de Chile para otorgar la custodia de las hijas de Atala Riffo a su ex cónyuge. Sin embargo, la Corte Suprema de Chile establece como punto de partida para el análisis, que la decisión de otorgar la custodia de las hijas al padre es una alternativa adecuada, a partir de la consideración de que la opción sexual de la madre puede afectar el interés superior del niño.

Al respecto, un elemento que tiene en cuenta la Corte IDH son los alcances del principio del interés superior del niño y precisa que su tutela o afectación no se define en abstracto, contrario sensu, este se define a partir de cada caso en concreto. En ese sentido, este principio tampoco puede ser un instrumento para afirmar prejuicios y criterios discriminatorios en contra de las "minorías" sexuales. En concreto, la Corte IDH afirmó que

[la] determinación del interés superior del niño, en casos de cuidado y custodia de menores de edad se debe hacer a partir de la evaluación de los comportamientos parentales específicos y su impacto negativo en el bienestar y desarrollo del niño según el caso, los daños o riesgos reales y probados, y no especulativos o imaginarios. Por tanto, no pueden ser admisibles las especulaciones, presunciones, estereotipos o consideraciones generalizadas sobre características 
personales de los padres o preferencias culturales respecto a ciertos conceptos tradicionales de la familia. ${ }^{17}$

A la vez, un factor relevante habría sido el de colocar de manera más explícita la diferencia en relación con un padre o madre heterosexual que pretende obtener la custodia de sus hijos o a quien se le deniega ello; este es un aspecto que le habría dado un mayor peso a la decisión, no obstante que en sí mismo, el caso podría calificarse como una especie de leading case.

Por otro lado, volviendo a la argumentación de la Corte IDH, conviene señalar que esta analizó los argumentos principales de la Corte Suprema de Chile relacionados con el interés superior del niño, que sustentaron la decisión que afectó los derechos de Atala Riffo. En principio, se evaluó que la presunta discriminación social que sufrirían las niñas al convivir con una madre lesbiana que vive con su pareja; al respecto, se indicó que es un argumento jurídico válido para intervenir en el derecho a la igualdad.

En relación con este aspecto, la Corte IDH afirmó que independientemente de los prejuicios o consideraciones de las sociedades, en las que puede haber cierto rango o nivel de intolerancia, debe tenerse en cuenta la realidad de las sociedades contemporáneas, en el que el concepto de familia ha variado, en ese sentido, las familias conformadas por padres y madres heterosexuales, no son las únicas manifestaciones de una opción de vida, sino que también se acepta las familias de padres solteros o padres divorciados, y en esa lógica no debería admitirse un argumento que rechace la conformación de una familia cuyos padres o madres tenga una distinta orientación sexual. ${ }^{18}$ En todo caso el estigma social debido a la orientación sexual de la madre o el padre no puede considerarse un "daño" valido a los efectos de la determinación del interés superior del niño. ${ }^{19}$

A su vez, se planteó otro aspecto, como el relativo a la supuesta confusión de roles que afectaría a las hijas de la señora Atala, pues la ausencia del padre, o en concreto, de una figura de sexo masculino y su reemplazo por una figura de género femenino, generaría un daño en la formación y desarrollo integral de las menores. En relación con ello, la Corte IDH apeló a una serie de estudios científicos e informes de especialistas a partir de los cuales concluyó que la convivencia de menores de edad con padres homosexuales no afecta per se su desarrollo emocional y psicológico.

7 CORTE IDH. Caso Atala Riffo y Niñas Vs. Chile, párr. 109.

18 CORTE IDH. Caso Atala Riffo y Niñas Vs. Chile, párr. 120.

19 CORTE IDH. Caso Atala Riffo y Niñas Vs. Chile, párr. 121. 
Asimismo, la Corte IDH también opuso a la argumentación de la Corte Suprema, el hecho de que esta no hubiera probado de manera adecuada las razones por las que la tutela a cargo del padre sería más favorable para las menores. En todo caso, la Corte IDH también afirmó que el hecho de que las menores tuvieran contacto con su padre, implicaba que estas no habían sido privadas del rol paterno. ${ }^{20}$

Otro argumento relevante dado por la Corte chilena sostiene que la madre había sobrepuesto sus intereses personales por encima de los de sus hijas, lo cual tampoco puede tener un adecuado fundamento jurídico, ya que, como se señalará más adelante, el reconocimiento y respeto a la orientación sexual es una parte intimamente ligada a la vida digan de una persona. Al respecto, la Corte IDH rebatió dicha posición señalando que "la orientación sexual de una persona también se encuentra ligada al concepto de libertad y la posibilidad de todo ser humano de auto-determinarse y escoger libremente las opciones y circunstancias que le dan sentido a su existencia, conforme a sus propias opciones y convicciones". ${ }^{21}$

En efecto, siendo la orientación sexual, un aspecto esencial de la identidad de Atala Riffo, habría sido ilegítimo exigirle que adecue su vida a una concepción tradicional del rol de la mujer como madre, en el que debía privilegiar los intereses de sus hijas conforme a los estándares de una sociedad intolerante, y que por ende pospusiera su proyecto de vida en pareja y de familia, en base a su orientación sexual. ${ }^{22}$

Por todo lo expuesto, la Corte IDH consideró que la orientación sexual sí fue un factor determinante para la discriminación en el caso de Karen Atala, en los siguientes términos:

[...] constata que la Corte Suprema de Justicia de Chile invocó las siguientes razones para fundamentar su sentencia: i) el presunto "deterioro experimentado por el entorno social, familiar y educacional en que se desenv[olvía] la existencia de las menores [de edad], desde que la madre empezó a convivir en el hogar con su pareja homosexual" y los "efectos que esa convivencia p[odía] causar en el bienestar y desarrollo psíquico y emocional de las hijas"; ii) la alegada existencia de una "situación de riesgo para el desarrollo integral de las menores [de edad] respecto de la cual deb[ían] ser protegidas" por "la eventual confusión de roles sexuales que p[odía] producírseles por la carencia en el hogar de un padre de sexo masculino y su

CORTE IDH. Caso Atala Riffo y Niñas Vs. Chile, párr. 123-131.

1 CORTE IDH. Caso Atala Riffo y Niñas Vs. Chile, párr. 136

22 CORTE IDH. Caso Atala Riffo y Niñas Vs. Chile, párr. 139-140. 
reemplazo por otra persona del género femenino"; iii) la supuesta existencia de "un estado de vulnerabilidad en su medio social" por el presunto riesgo de una estigmatización social, y iv) la priorización de los intereses de la señora Atala a los de las menores de edad "al tomar la decisión de explicitar su condición homosexual"118. Estos argumentos y el lenguaje utilizado muestran un vínculo entre la sentencia y el hecho que la señora Atala vivía con una pareja del mismo sexo, lo cual indica que la Corte Suprema otorgó relevancia significativa a su orientación sexual. ${ }^{23}$

\subsection{Derecho a la vida privada y orientación sexual}

La Convención Americana sobre Derechos Humanos establece en su artículo 11 la "Protección de la Honra y de la Dignidad", que, a juicio de la Corte Interamericana, hace referencia al derecho a la vida privada: ${ }^{24}$

1. Toda persona tiene derecho al respeto de su honra y al reconocimiento de su dignidad.

2. Nadie puede ser objeto de injerencias arbitrarias o abusivas en su vida privada, en la de su familia, en su domicilio o en su correspondencia, ni de ataques ilegales a su honra o reputación.

3. Toda persona tiene derecho a la protección de la ley contra esas injerencias o esos ataques.

De esta forma, la Corte IDH estableció que la esfera de la privacidad de la persona debe quedar ajena a las invasiones o agresiones abusivas por parte de terceros o incluso del Estado. ${ }^{25}$ Señala la Corte IDH que "la vida privada es un concepto amplio que no es susceptible de definiciones exhaustivas y comprende, entre otros ámbitos protegidos, la vida sexual y el derecho a establecer y desarrollar relaciones con otros seres. Es decir, la vida privada incluye la forma en que el individuo se ve a sí mismo y cómo y cuándo decide proyectar a los demás". ${ }^{26}$

En tal supuesto, la libertad sexual -la cual, como se ha señalado, comprende la orientación sexual y la identidad de género- se encuentra dentro de la protección convencional de la vida privada. Por tanto, una interferencia del Estado

\footnotetext{
CORTE IDH. Caso de las Masacres de Ituango Vs. Colombia, párr. 194

CORTE IDH. Caso Atala Riffo y Niñas Vs. Chile, párr. 162.

CORTE IDH. Caso de las Masacres de Ituango Vs. Colombia, párr. 194.

CORTE IDH. Caso Atala Riffo y Niñas Vs. Chile, párr. 162.
} 
en cuanto a la libertad sexual de una persona debe cumplir con los requisitos de proporcionalidad ${ }^{27}$ y razonabilidad, ya que podría significar una disminución del goce de un derecho fundamental.

En lo referido al caso concreto, la Corte IDH señaló, como se ha mencionado, que la decisión de la Corte Suprema sobre la provación de la tuición de sus hijas fue un acto de discriminación, y además a lo largo del proceso se expusieron públicamente diversos aspectos de su vida privada. Si bien in abstracto el interés superior de las niñas constituye un fin legítimo, "la medida era inadecuada y desproporcionada para cumplir este fin, por cuanto los tribunales chilenos tendrían que haberse limitado a estudiar conductas parentales -que podian ser parte de la vida privada- pero sin efectuar una exposición y escrutinio de la orientación sexual de la señora Atala". ${ }^{28}$

Además, recordando el citado artículo 11 de la Convención Americana, el derecho fundamental a la vida privada no solo involucra a la persona en sí, sino también a su familia. De hecho, la Corte IDH consideró que el derecho a la protección de la familia también se encuentra protegido por el artículo 17.1 de la Convención. Al respecto, conviene recordar que la orientación sexual o identidad de género no son un impedimento para la formación de una familia, según el principio 24 de los Principios de Yogyakarta:

Principio 24.- El derecho a formar una familia.

Toda persona tiene el derecho a formar una familia, con independencia de su orientación sexual o identidad de género. Existen diversas configuraciones de familias. Ninguna familia puede ser sometida a discriminación basada en la orientación sexual o identidad de género de cualquiera de sus integrantes.

Los Estados:

Adoptarán todas las medidas legislativas, administrativas y de otra índole que sean necesarias a fin de asegurar el derecho a formar una familia, incluso a través del acceso a adopción o a reproducción asistida (incluyendo la inseminación por donante), sin discriminación por motivos de orientación sexual o identidad de género.

27 CORTE IDH. Caso Atala Riffo y Niñas Vs. Chile, párr. 165.

28 CORTE IDH. Caso Atala Riffo y Niñas Vs. Chile, párr. 166. 
En concreto, se indicó que el concepto de familia, no involucra únicamente al matrimonio, sino a otras formas de tener una vida en común, para lo cual la Corte Interamericana hizo referencia al Caso $X, Y$ y $Z$ vs. Reino Unido, en el que el Tribunal Europeo de Derechos Humanos reconoció que un transexual, su pareja mujer y un niño pueden configurar una familia. En el caso en concreto, el Tribunal interamericano consideró que la Corte Suprema chilena había vulnerado el derecho a la protección de la familia en la medida que hasta antes de la emisión de su fallo, la señora Atala, sus hijas, así como su pareja habían constituido un núcleo familiar, en el que existía una convivencia, un contacto frecuente, y una cercanía personal y afectiva entre cada uno de ellos. ${ }^{29}$

En líneas generales, en el caso de Karen Atala, se vulneró de una manera ilegítima, desproporcionada e irracional su derecho a la vida privada, ya que en el proceso se expuso públicamente su vida personal, así como su vida familiar, basándose en estereotipos patriarcales que in concreto no defendían verdaderamente un fin constitucional.

\section{Reproducción sexual asistida: Artavia Murillo y otros vs. Costa Rica}

En febrero de 1995 el gobierno de Costa Rica emitió el Decreto Ejecutivo No. 24029-S, el cual autorizaba la práctica de la fecundación in vitro (FIV) para parejas conyugales y regulaba su ejecución. En su artículo $1^{\circ}$ el Decreto Ejecutivo estableció técnicas de reproducción asistida entre cónyuges y las reglas para su realización. La FIV fue practicada en Costa Rica entre 1995 y 2000 y en ese lapso nacieron 15 costarricenses. ${ }^{30}$ Sin embargo, en abril del mismo año se presentó contra el Decreto Ejecutivo una acción de inconstitucionalidad alegando que la fertilización artificial in vitro suponía una violación al derecho a la vida del concebido, por lo que en el año 2000 la Sala Constitucional de la Corte Suprema declaró su inconstitucionalidad.

La Sala Constitucional fundamentó su decisión en que: (i) el Decreto Ejecutivo regulaba el "derecho a la vida y a la dignidad del ser humano", razón por la cual "[l]a regulación de estos derechos por el Poder Ejecutivo resulta[ba] incompatible con el Derecho de la Constitución", y consecuentemente se vulneraría el principio de reserva legal; y (ii) la fertilización in vitro atenta contra la vida y dignidad del ser humano. El último argumento se esgrimió a raíz de la teoría que sostiene que la

CORTE IDH. Caso Atala Riffo y Niñas Vs. Chile, párr. 176-178.

30 CORTE IDH. Caso Atala Riffo y Niñas Vs. Chile, Resumen oficial, p. 3. 
vida tiene protección legal desde la concepción entendida como fecundación unión de los espermatozoides con el óvulo-, y desde tal punto de vista se estaría utilizando al embrión para fines de investigación, es decir, como un medio y no un fin en sí mismo.

La sexualidad y la reproducción constituyen dimensiones básicas del desarrollo de cada persona, varón o mujer, y por lo tanto de la salud individual. Es por eso que el derecho a la salud constituye un derecho humano esencial, y los derechos sexuales y reproductivos se reconocen como parte integral de los derechos humanos. ${ }^{31}$

Para analizar a mayor profundidad la sentencia de la Sala Constitucional costarricense, convendrá señalar en primer lugar qué derechos fundamentales están relacionados al derecho a la reproducción asistida. Posteriormente, deberá analizarse el caso concreto en cuanto a los derechos que confronta.

\subsection{Derechos sexuales y reproductivos}

En la Conferencia Internacional sobre Población y Desarrollo de la ONU, realizada en El Cairo en 1994, se definieron los derechos reproductivos a partir del concepto de salud reproductiva. Esta última es definida como:

(...) un estado general de bienestar físico, mental y social, y no de mera ausencia de enfermedades o dolencias, en todos los aspectos relacionados con el sistema reproductivo y sus funciones y procesos. [Asimismo] la atención de la salud reproductiva se define como el conjunto de métodos, técnicas y servicios que contribuyen a la salud y al bienestar reproductivos al evitar y resolver los problemas relacionados con la salud reproductiva. Incluye también la salud sexual, cuyo objetivo es el desarrollo de la vida y de las relaciones personales y no meramente el asesoramiento y la atención en materia de reproducción y de enfermedades de transmisión sexual. ${ }^{32}$

A partir de dicha definición, los derechos sexuales y reproductivos abarcan ciertos derechos humanos que se basan en el reconocimiento del derecho de todas las parejas e individuos a decidir de manera libre y responsable sobre

31 SPASIUK, Gisela Elizabeth y Zulma CABRERA (2009): 4-5.

32 ORGANIZACIÓN DE LAS NACIONES UNIDAS (1994): párr. 7.2. 
sus relaciones sexuales, así como el número de hijos que quieran tener y el espaciamiento de los nacimientos e intervalo entre estos. ${ }^{33}$

En consecuencia, los derechos sexuales y reproductivos son aquellos que protegen las funciones reproductivas de las personas de manera integral, es decir, la capacidad de toda persona de decidir cómo, cuándo y con quien reproducirse. Asimismo, la doctrina ha definido a los derechos sexuales y reproductivo como aquellos derechos "que implican la libre determinación sobre la propia fertilidad, que incluyen el derecho a tener o a no tener hijos, cuantos y con qué frecuencia, y bajo qué condiciones personales o de pareja se toma tal decisión, sin ningún tipo de coacción, discriminación ni violencia". ${ }^{34}$

\subsection{Alcances y límites de los derechos reproductivos}

Como resulta evidente, los derechos reproductivos no son una esfera aislada de los demás derechos fundamentales de la persona, en especial en cuanto a sus derechos personalísimos. Incluye los derechos de las personas (i) a no morir por causas evitables que están relacionadas con el embarazo y el parto, (ii) a la salud sexual y reproductiva, (iii) a la autonomía reproductiva, (iv) a decidir libremente su función reproductiva, sin injerencias arbitrarias y (v) a adoptar decisiones sobre la reproducción sin sufrir discriminación. ${ }^{35}$

Por tanto, todos estos derechos se relacionan a la autonomía y autodeterminación de la paternidad y maternidad responsables, así como al derecho a la integridad física o del propio cuerpo de las personas. Por ello:

Todas las personas tienen el derecho a reproducirse y este forma parte de su derecho a tomar decisiones vitales y a organizarse familiarmente. Por su parte, los poderes públicos desempeñan un papel pasivo que consiste en abstenerse de imponer límites o interferir o controlar este tipo de decisiones, salvo situaciones extremas. ${ }^{36}$

Entonces, todas las personas tienen libertad sobre su propio cuerpo respecto a la reproducción y podría decirse que existe tanto una dimensión positiva de los mismos, que puede entenderse como la decisión de la persona de reproducirse, así como una dimensión negativa, que implica el derecho a no hacerlo, como podría ser la esterilización voluntaria.

ORGANIZACIÓN DE LAS NACIONES UNIDAS (1994): párr. 7.3.

34 SPASIUK, Gisela Elizabeth y Zulma CABRERA (2009): 4.

35 RAMÍREZ HUAROTO, Beatriz (s/fecha): 366.

36 BRENA, Ingrid (2013): 795-803. 
Todo lo dicho se torna más complejo con los problemas de la infertilidad, ya que el derecho a la procreación adquiere matices diferentes. En América Latina los métodos más utilizados para resolver casos de infertilidad son la inseminación artificial y la fertilización in vitro. Respecto a estos mecanismos, existe una doble obligación del Estado. El Estado tiene el deber de no impedir u obstaculizar el acceso a dichos tratamientos (obligación negativa), así como el de facilitar la información y los medios de acceso a estos. ${ }^{37}$

El derecho a la procreación para las personas infértiles supone el derecho de acceso a la información y los medios para la reproducción asistida, ya que este es el derecho a hacer efectiva la procreación mediante tratamientos médicos y conforme a los nuevos avances científicos. Por el contrario, negar el acceso a la reproducción asistida constituiría una violación del Estado al deber garantizar y proteger la salud reproductiva de sus ciudadanos.

Dentro de esa lógica, el Sistema Interamericano de Derechos Humanos en su interpretación expansiva le otorga a los derechos reproductivos un auténtico estatus de derechos fundamentales. Así, Corte IDH ha establecido en la sentencia de Artavia Murillo vs. Costa Rica, que los Estados tienen el deber de "regular y fiscalizar la prestación de los servicios de salud para lograr una efectiva protección de los derechos a la vida y a la integridad personal"; asimismo, que "la falta de salvaguardas legales para tomar en consideración la salud reproductiva puede resultar en un menoscabo grave del derecho a la autonomía y la libertad reproductiva".

De aquello se deduce que existe efectivamente una obligación para los Estados de garantizar que las personas reciban la atención médica que requieren cuando se vea amenazada su vida, integridad o su salud, y, que esta garantía institucional de protección de la persona humana tenga como contra partida el rol del Estado de hacerla cumplir, inclusive a pesar de la objeción de conciencia que los médicos profesionales pudieran tener. ${ }^{38}$

\subsubsection{Embriones y derecho a la vida}

La vida es el derecho fundamental que tienen todas las personas a no ser privados arbitrariamente de ella; Asimismo, la vida es un derecho necesario para concretizar los demás derechos de los cuales el ser humano es titular. A nivel internacional, el derecho a la vida tiene protección en distintos tratados de

37 BRENA, Ingrid (2013): p. 798

38 CENTRO DE DERECHOS REPRODUCTIVOS (s/fecha): 4. 
derechos humanos, tales como la Declaración Universal de Derechos Humanos. ${ }^{39}$ Específicamente a nivel latinoamericano, este derecho fundamental se encuentra protegido en la Convención Americana sobre Derechos Humanos, ${ }^{40}$ y también el Pacto Internacional de Derechos Políticos y Civiles. ${ }^{41}$

El derecho a la vida tiene un doble carácter, ya que es tanto un principio constitucional que sirve para dar contenido e interpretar otros derechos y disposiciones, y es un derecho, en tanto tiene reconocimiento como base de otros derechos y debe ser protegido y en consecuencia exigible de tutela por el ordenamiento jurídico.

Respecto al derecho a la vida de todas las personas, Villavicencio considera que su protección:

[...] es indiscutible e incuestionable, con independencia de su status, pre- o postnatal, de su capacidad o incapacidad de vida o de la mayor o menor calidad de vida. Se trata de un derecho de todo ser humano desde su concepción hasta su muerte, haya adquirido la calidad de persona o se encuentre todavía en el vientre materno. Sin embargo, la intensidad de la protección de la vida fetal y del ya nacido es diferente en los distintos ordenamientos positivos, según se halle en el seno materno o fuera de él. ${ }^{42}$

Debe recordarse que ningún derecho es absoluto, y puede ser legítimamente limitado cuando sea para asegurar el goce de otro derecho fundamental, siempre que dicha intromisión se produzca bajo los principios de razonabilidad y proporcionalidad. La vida, a pesar de ser el derecho base para el goce de todos los demás derechos, prima facie no puede ni se presenta como un derecho absoluto tampoco. Es entonces cuando se plantean los problemas bioéticos en relación a los derechos sexuales y reproductivos.

Recordemos que los derechos reproductivos abarcan una amplia esfera de libertad de las personas para reproducirse, e involucra desde la facilitación de la información y los medios para la reproducción asistida en casos de incapacidad natural, hasta la posibilidad de interrumpir el embarazo en los supuestos permitidos por ley, poniendo en cuestión el derecho al proyecto de vida del nasciturus.

\footnotetext{
39 Artículo 3.- "Todo individuo tiene derecho a la vida, a la libertad y a la seguridad de su persona".

40 Artículo 4.- Derecho a la Vida "1. Toda persona tiene derecho a que se respete su vida. Este derecho estará protegido por la ley y, en general, a partir del momento de la concepción. Nadie puede ser privado de la vida arbitrariamente".

41 Artículo 6.- "1. El derecho a la vida es inherente a la persona humana. Este derecho estará protegido por la ley. Nadie podrá ser privado de la vida arbitrariamente (...)"

42 VILLAVICENCIO TERREROS, Felipe (s/fecha): 1-2.
} 
En efecto, en la mayoría de los países de América Latina se reconoce el aborto terapéutico, en el cual se limita la vida del feto o embrión en casos que represente un grave riesgo para la vida o un mal grave y permanente para la salud de la gestante. ${ }^{43}$ El aborto terapéutico es el aborto que presenta la mayor regularización en América Latina, y en muchos países es el único legalizado. Son pocos los países en la región latina que manejan una política de prohibición total al aborto, como es el caso de Chile, aunque en la actualidad eso se encuentra en debate. ${ }^{44}$

Las legislaciones latinoamericanas presentan una pluralidad de concepciones en cuanto al derecho a la vida. Así, la región latinoamericana, se presenta al nasciturus como un "sujeto de derecho" o ente con "capacidad jurídica”. Por ejemplo, los códigos civiles de Argentina, Perú y Paraguay protegen al nasciturus como sujeto de derecho desde la concepción. ${ }^{45}$ Sobre el particular, hay un extendido debate en torno al origen de la vida humana y de su protección jurídica; unos, plantean que la protección jurídica de la vida debe darse desde la fecundación -unión de los espermatozoides con el óvulo-, otros, plantean que la protección jurídica de la vida solo es posible desde la anidación del óvulo fecundado -embrión- en las paredes del endometrio del útero, en la medida que solo a partir de entonces se hace viable el proyecto de vida humana.

Al respecto, se podría decir que si bien no existe un consenso en Latinoamérica sobre el inicio de la vida, la Corte IDH optó por la teoría de la anidación como concepto que se desprende del artículo 4.1 de la CADH. Para ello aplicó criterios como el del objeto y fin del tratado y el de la interpretación evolutiva, para lo cual empleó los desarrollos científicos pertinentes en el derecho internacional y comparado respecto al status legal del embrión, y las regulaciones y prácticas del derecho comparado en relación con la Fecundación In Vitro (FIV). ${ }^{46}$

Así, la Corte IDH interpretó el artículo 4.1 de la CADH que señala de manera expresa que el derecho a la vida está protegido por la ley de manera progresiva. En concreto, señaló que en el Sistema Universal de Derechos Humanos, como en los Sistemas Europeo y Africano de Derechos Humanos, se reconocía que el derecho del "no nacido" no era absoluto. ${ }^{47}$

43 Cfr. En el Perú la Guía Técnica Nacional para la estandarización del procedimiento de la Atención Integral de la gestante en la Interrupción Voluntaria por Indicación Terapéutica del Embarazo menor de 22 semanas con el consentimiento informado en el marco de lo dispuesto en el artículo 119 del Código Penal. Promulgado el 27 de junio de 2014.

44 Cfr. Cámara de Diputados de la República de Chile (2015): Proyecto de Ley que regula la despenalización del aborto en tres causales. <http://www.camara.cl/pley/pley_detalle.aspx?prmID=10315\& prmBL=9895-11>. Consulta el 16 de marzo de 2015

45 DELGADO SCHNEIDER, Verónica Pía (s/fecha): 95-108.

46 CORTE IDH. Caso Artavia Murillo y otros vs. Costa Rica, párr. 246.

47 CORTE IDH. Caso Artavia Murillo y otros vs. Costa Rica, párr. 254 y subsiguientes. 
En el caso de Artavia Murillo y otros vs. Costa Rica, sin duda, la mayor controversia que tuvo que resolver la Sala Constitucional costarricense fue la del derecho a la vida del embrión. En la fertilización in vitro, las fases son: “i) inducción a la ovulación; ii) aspiración de los óvulos contenidos en los ovarios; iii) inseminación de óvulos con espermatozoides; iv) observación del proceso de fecundación e incubación de los embriones, y v) transferencia embrionaria al útero materno". ${ }^{48}$

A juicio de la Sala Constitucional de la Corte Suprema de Costa Rica, era un problema que no todos los embriones fueran implantados en el útero materno; por cuanto, consideraban que desde la inseminación artificial, es decir el encuentro de los espermatozoides con el óvulo se forma el cigoto -pre embrión-, con el cual se da inicio a la vida humana. En efecto, para la Sala Constitucional, siguiendo la teoría de la fecundación, señaló que desde el origen de la vida del nasciturus tiene protección constitucional; por lo cual, desechar algunos pre embriones luego de la inseminación artificial, estaría vulnerando el derecho a la vida del concebido.

Sin embargo, llegado a este punto conviene precisar que en materia de protección al derecho a la vida, la teoría de la anidación postula que la vida protegida jurídicamente se inicia cuando el embrión en forma de cigoto se anida en la pared del endometrio materno, ${ }^{49}$ es decir, al momento de implantación del óvulo fecundado en el útero. Ahora bien, para la Corte IDH debe interpretarse a la concepción, en el sentido de la anidación o implantación. Esto es debido a que "la Corte entiende que el término "concepción" no puede ser comprendido como un momento o proceso excluyente del cuerpo de la mujer, dado que un embrión no tiene ninguna posibilidad de supervivencia si la implantación no sucede". 50

Por tanto, puede afirmarse que si bien al nasciturus desde la concepción, en tanto pre embrión se le reconoce como proyecto de vida (aunque, por supuesto, no como derecho absoluto), adquiere plena protección jurídica cuando el embrión resulta viable que se convierta en persona. ${ }^{51}$ Por eso, la Corte IDH ha señalado que: “[...] la Corte concluye que la interpretación histórica y sistemática de los antecedentes existentes en el Sistema Interamericano, confirma que no es procedente otorgar el estatus de persona al embrión". ${ }^{52}$

Asimismo, respecto a la protección internacional del derecho a la vida, es decir, los referidos artículo 4 de la Convención Americana, el artículo 3 de la Declaración Universal, el artículo 6 del Pacto Internacional de Derechos Civiles

8 CORTE IDH. Caso Artavia Murillo y otros vs. Costa Rica, párr. 22.

49 TRIBUNAL CONSTITUCIONAL DEL PERÚ. Sentencia 02005-2009-PA/TC. Fundamento jurídico 14.

50 CORTE IDH. Caso Artavia Murillo y otros vs. Costa Rica, párr. 188.

51 DÍAZ REVORIO, Francisco Javier (2009): 125-13.

52 CORTE IDH. Caso Artavia Murillo y otros vs. Costa Rica, párr. 223. 
y Políticos, la Convención sobre los Derechos del Niño y la Declaración de los Derechos del Niño, la Corte IDH concluyó que:

de ninguno de estos artículos o tratados es posible sustentar que el embrión pueda ser considerado persona en los términos del artículo 4 de la Convención. Tampoco es posible desprender dicha conclusión de los trabajos preparatorios o de una interpretación sistemática de los derechos consagrados en la Convención Americana o en la Declaración Americana. ${ }^{53}$

Por tanto, desde el punto de vista de la Corte IDH, no puede deducirse que el derecho a la vida del nasciturus empiece desde la concepción entendida como la fecundación del óvulo por los espermatozoides, sino en tanto el embrión ya se encuentre anidado en las paredes del endometrio del útero de la mujer.

\subsubsection{Derecho a la reproducción asistida y vida privada}

La Corte IDH estimó que una vulneración al derecho a la reproducción asistida supone directamente una injerencia arbitraria en la vida privada. De manera similar al caso de Atala Riffo vs. Chile, la Corte señaló que el Estado debe proteger a las personas frente a acciones arbitrarias de instituciones estatales que afectan la vida privada y familiar. ${ }^{54}$ Además, una precisión adicional de la Corte IDH establece que el derecho a la reproducción asistida no es sinónimo de privacidad, sino que es más amplio, ya que tiene íntima relación con la dignidad de la persona. Visto de esta manera, el "concepto de vida privada engloba aspectos de la identidad física y social, incluyendo el derecho a la autonomía personal, desarrollo personal y el derecho a establecer y desarrollar relaciones con otros seres humanos y con el mundo exterior". ${ }^{55}$

Por tanto, el derecho a la vida privada y familiar no es una mera protección a la intimidad de la persona y su familia; sino, también se manifiesta como el derecho de las personas de evitar injerencias arbitrarias del Estado. La reproducción, como es evidente, es una esfera personal e íntima del ser humano en donde debe primar la autonomía, la libertad y el respeto por la integridad, sin la intervención de terceros o sin el consentimiento de la persona interesada.

53 CORTE IDH. Caso Artavia Murillo y otros vs. Costa Rica, párr. 244.

54 CORTE IDH. Caso Artavia Murillo y otros vs. Costa Rica, párr. 142.

55 CORTE IDH. Caso Artavia Murillo y otros vs. Costa Rica, párr. 143. 
En ese entendido, el Estado constitucional promueve el matrimonio y otorga especial protección a la familia, como núcleos de reproducción de la sociedad, y aquello es un común denominador en las legislaciones latinoamericanas. En el ámbito del Derecho Internacional, ya desde 1948 en la Declaración Universal se hablaba de la importancia de la familia en la sociedad, al señalar en el artículo 16 que:

1. Los hombres y las mujeres, a partir de la edad núbil, tienen derecho, sin restricción alguna por motivos de raza, nacionalidad, o religión, a casarse y a fundar una familia; y disfrutarán de iguales derechos en cuanto al matrimonio, durante el matrimonio y en caso de disolución del matrimonio. [...] 3. La familia es el elemento natural y fundamental de la sociedad y tiene derecho a la protección de la sociedad y del Estado.

Los avances científicos en materia de reproducción asistida son medidas útiles para lograr la fundación de una familia en los casos donde no es posible por medios naturales, como por ejemplo en los casos de infertilidad. En un informe de la Comisión Interamericana (Acceso a la Información Reproductiva desde una perspectiva de Derechos Humanos), se precisa que las mujeres deben contar con suficiente información para tomar decisiones sobre su salud y que el acceso a la información en materia reproductiva "contribuye a que las mujeres puedan tomar decisiones informadas sobre la esfera más íntima de su persona como decidir tener hijos". ${ }^{56}$ Es decir, el Sistema Interamericano reconoce que las mujeres pueden decidir la manera más beneficiosa para tener hijos como un ejercicio legítimo de su libertad y autonomía, así como parte de su derecho a la vida privada y familiar.

Asimismo, la Convención para la Eliminación de todas las Formas de Discriminación contra la Mujer (CEDAW, por sus siglas en inglés) establece derechos para las mujeres en el ámbito familiar, e incluye en dicha protección a la vida privada y familiar el derecho fundamental a la autonomía reproductiva:

Artículo 16.-

1. Los Estados Partes adoptarán todas las medidas adecuadas para eliminar la discriminación contra la mujer en todos los asuntos relacionados con el matrimonio y las relaciones familiares $\mathrm{y}$, en particular, asegurarán, en condiciones de igualdad entre hombres y mujeres:

56 COMISIÓN INTERAMERICANA DE DERECHOS HUMANOS (2011): párrafo 47. 
a. El mismo derecho para contraer matrimonio; (...)

e. Los mismos derechos a decidir libre y responsablemente el número de sus hijos y el intervalo entre los nacimientos y a tener acceso la información, la educación y los medios que les permitan ejercer estos derechos (...).

De esta manera, la Corte IDH establece que la protección a la vida privada involucra un respeto hacia las decisiones de convertirse en padre o madre, y esto incluye "la decisión de la pareja de convertirse en padres genéticos". ${ }^{57}$

La Corte ha precisado que el derecho a la vida privada guarda directamente relación con la autonomía reproductiva y el acceso a servicios de salud reproductiva, lo cual involucra también el acceso a la tecnología médica necesaria para ejercer ese derecho. ${ }^{58}$ Los avances científicos en materia de reproducción asistida son medidas útiles para lograr la fundación de una familia en los casos donde no es posible por medios naturales, como por ejemplo en los casos de infertilidad.

Para tal efecto, a juicio de la Comisión Interamericana (Acceso a la Información Reproductiva desde una perspectiva de Derechos Humanos), se precisa que las mujeres deben contar con suficiente información para tomar decisiones sobre su salud y que el acceso a la información en materia reproductiva "contribuye a que las mujeres puedan tomar decisiones informadas sobre la esfera más íntima de su persona como decidir tener hijos". ${ }^{59}$ Es decir, el Sistema Interamericano reconoce que las mujeres pueden decidir la manera más beneficiosa para tener hijos como un ejercicio legítimo de su libertad y autonomía, así como parte de su derecho a la vida privada y familiar.

\subsubsection{Derecho a la salud sexual reproductiva}

El derecho a la integridad goza de protección internacional a nivel latinoamericano con el Pacto de San José, ${ }^{60}$ en el cual se agregaron las dimensiones psicológica y moral del derecho a la integridad, alejándose de la concepción clásica de reducir la integridad a un aspecto físico. La Organización Mundial de la Salud señala que la salud no se limita únicamente a la esfera física, sino que abarca un bienestar integral, que también incluye una dimensión mental y social. Si la

\footnotetext{
CORTE IDH. Caso Artavia Murillo y otros vs. Costa Rica. Fundamento jurídico 146.

Ídem.

59 COMISIÓN INTERAMERICANA DE DERECHOS HUMANOS. Acceso a la información...; párrafo 47.

60 Artículo 5.- Derecho a la Integridad Personal

“1. Toda persona tiene derecho a que se respete su integridad física, psíquica y moral (...)”.
} 
salud mental se define como un "estado de bienestar en el cual el individuo es consciente de sus propias capacidades, puede afrontar las tensiones normales de la vida, puede trabajar de forma productiva y fructífera y es capaz de hacer una contribución a su comunidad". ${ }^{61}$ Por ello, es claro que una intromisión arbitraria en la vida privada y familiar de una persona tendrá una afectación directa en la salud mental.

La Corte IDH resaltó la jurisprudencia del Tribunal Europeo de Derechos Humanos que determina que existe una estrecha correlación entre la protección a la vida privada y el derecho a la integridad física y psicológica. El Estado tiene el deber de garantizar el derecho a la integridad en relación con su vida privada personal y familiar. Enfatiza la Corte IDH que "la falta de salvaguardas legales para tomar en consideración la salud reproductiva puede resultar en un menoscabo grave del derecho a la autonomía y la libertad reproductiva. Existe por tanto una conexión entre la autonomía personal, la libertad reproductiva y la integridad física y psicológica". 62

Además, enfocándonos en los derechos reproductivos, el Programa de Acción de la Conferencia Internacional sobre la Población y el Desarrollo de las Naciones Unidas ${ }^{63}$ ha definido a la salud reproductiva como: "un estado general de bienestar físico, mental y social, y no de mera ausencia de enfermedades o dolencias, en todos los aspectos relacionados con el sistema reproductivo y sus funciones y procesos". Aquello es conforme a la concepción de la salud dada por la Organización Mundial de la Salud, es decir, se entiende a la salud reproductiva como un elemento constitutivo del bienestar general, en tanto permite el libre desarrollo de la persona humana y la realización de su proyecto de vida.

Por tanto, al privar a las personas que padecen infertilidad de acceder a métodos alternativos para ejercer su derecho a la procreación, como es la reproducción asistida mediante la fertilización in vitro, se les priva del ejercicio de su salud reproductiva, y consecuentemente representa una severa intromisión al derecho a la integridad de las personas; lo cual afecta su libre desarrollo humano. Si bien el derecho a la salud no es sinónimo de derecho a la integridad, esta debe ser frecuentemente protegida a fin de garantizar aquella. ${ }^{64}$

61 Ver ORGANIZACIÓN MUNDIAL DE LA SALUD. Salud mental: un estado de bienestar. Diciembre de 2013. Disponible en web: http://www.who.int/features/factfiles/mental_health/es/. Consulta realizada el 10 de febrero de 2015.

62 CORTE IDH. Caso Artavia Murillo y otros vs. Costa Rica, párr. 147.

63 ORGANIZACIÓN MUNDIAL DE LA SALUD (2013): s/página.

64 CANOSA, Raúl (2006): 106. 


\subsubsection{Derecho a la igualdad y no discriminación por infertilidad (discapacidad)}

Como se ha señalado respecto a la sentencia de Atala Riffo vs. Costa Rica, el derecho fundamental a la igualdad tiene tres dimensiones: ante la ley, en la aplicación de la ley y en el trato. De manera directa, la medida regulatoria de la fertilización in vitro no resulta en principio discriminatoria; por cuanto, la ley se dirige de manera general a todos los ciudadanos, sin hacer excepción de personas.

Sin embargo, la discriminación no significa exclusivamente que una ley pueda estar explícitamente dirigida a un grupo de personas y carezca de razonabilidad y proporcionalidad. Por el contrario, puede también darse el caso de que la ley ocasione lo que se conoce como una discriminación indirecta. Aquello significa que, si bien taxativamente la ley no hace una diferenciación injustificada entre las personas, en la práctica un grupo se ve notablemente más perjudicado que el resto de la sociedad.

En el caso de la fertilización in vitro, la Corte IDH estimó que la decisión de la Sala Constitucional costarricense ocasionaba discriminación indirecta a las personas infértiles, en tanto esta constituye una discapacidad. En tanto que la discapacidad "no se define exclusivamente por la presencia de una deficiencia física, mental, intelectual o sensorial, sino que se interrelaciona con las barreras o limitaciones que socialmente existen para que las personas puedan ejercer sus derechos de manera efectiva". 65

En ese sentido, la infertilidad podría ser considerada una discapacidad, puesto que es una limitación a la salud reproductiva que permite el ejercicio efectivo del derecho a la procreación, mediante la reproducción asistida. En vista de ello, las personas con infertilidad debían ser protegidas por los Estados con el estatus de los derechos de los discapacitados, entre los cuales se incluye el derecho de acceder a las técnicas necesarias para resolver problemas de salud reproductiva. ${ }^{66}$

Además, existe un problema adicional de fuerte carácter social e íntimamente ligada a los estereotipos de género. En una sociedad como la latinoamericana, la feminidad se identifica en gran medida con la maternidad; lo cual hace que aumente el sufrimiento de las mujeres que padecen infertilidad y que no pueden acceder a la reproducción asistida. ${ }^{67}$ En cuanto a los hombres, la infertilidad ocasiona un sentimiento de impotencia que puede llevar a cuestionarse su identidad de género

CORTE IDH. Caso Artavia Murillo y otros vs. Costa Rica, párr. 291.

66 CORTE IDH. Caso Artavia Murillo y otros vs. Costa Rica, párr. 293.

67 CORTE IDH. Caso Artavia Murillo y otros vs. Costa Rica, párr. 296. 
debido a los estereotipos sociales patriarcales. Si bien la Corte no valida dichos estereotipos, "Ios reconoce y visibiliza para precisar el impacto desproporcionado de la interferencia". 68

Finalmente, existe otro tipo de discriminación, aparte de la discriminación por discapacidad. ${ }^{69}$ Se trata de la discriminación por situación económica. A juicio de la Corte IDH, la medida que prohíbe la fertilización in vitro en Costa Rica ocasionará que solamente quienes tienen la capacidad económica de llevar el tratamiento en el extranjero podrán gozar del derecho a la reproducción asistida; mientras que, las personas infértiles que no puedan disponer del dinero no podrán hacer efectivo su derecho a la procreación.

Por tanto, en última instancia, la medida solo sería un obstáculo, un impedimento que solo los más adinerados podrán superar. Aquello es además socialmente discriminatorio y va en contra de todo principio constitucional a la igualdad no slo ante la ley, sino también igualdad de oportunidad y de trato; ya que se castiga a la pobreza y convierte a la riqueza como un requisito esencial para el ejercicio de un derecho fundamental a la salud reproductiva que como tal debe ser inherente a todo ser humano.

\subsection{Proporcionalidad de la medida}

La Corte IDH estima que una injerencia en un derecho es legítima o al menos no arbitraria, cuando dicha injerencia esta prevista en ley en sentido formal y material, persigue un fin legítimo y cumple con los requisitos de idoneidad, necesidad y proporcionalidad. Empero, la Corte evaluó la proporcionalidad de la medida siguiendo el modelo norteamericano, a diferencia del modelo europeo empleado en la sentencia de Atala Riffo vs. Chile. Para ello, se analizó “i) el grado de afectación de uno de los bienes en juego, determinando si la intensidad de dicha afectación fue grave, intermedia o moderada; ii) la importancia de la satisfacción del bien contrario, y iii) si la satisfacción de éste justifica la restricción del otro". ${ }^{70}$

8 CORTE IDH. Caso Artavia Murillo y otros vs. Costa Rica, párr. 302

CORTE IDH. Caso Artavia Murillo y otros vs. Costa Rica, párr. 304.

70 CORTE IDH. Caso Artavia Murillo y otros vs. Costa Rica, párr. 274. 


\subsubsection{Grado de afectación}

A juicio de la Corte IDH se vulneraron de forma severa: por un lado, los derechos a la integridad y a la libertad personal, en relación a la autonomía reproductiva, y; por otro, los derechos a la vida privada y familiar, así como, a la igualdad y no discriminación. Lo que supuso una violación de dichos derechos y que en la práctica fueran anulados de manera discriminatoria, dado que únicamente afectaron a "personas cuyo único tratamiento posible de la infertilidad era la FIV". ${ }^{71}$

\subsubsection{Importancia de satisfacción del bien contrario}

Para la Corte IDH, como la anidación es el momento de certeza del derecho a la vida "dado que la pérdida embrionaria se presenta tanto en la FIV como en el embarazo natural", ${ }^{72}$ la protección del embrión es leve. Por eso, antes de la implantación en el útero materno el embrión no se encuentra protegido por el artículo 4 de la Convención IDH.

\subsubsection{Justificación de la restricción}

A juicio de la Corte IDH la decisión de la Sala Constitucional de la Corte Suprema de Costa Rica, la restricción fue desproporcionada y tuvo efectos discriminatorios para las persona que padecen de infertilidad. Además, para la Corte, dicha Sala "partió de una protección absoluta del embrión que, al no ponderar ni tener en cuenta los otros derechos en conflicto, implicó una arbitraria y excesiva intervención". ${ }^{73}$

En concreto, la Corte IDH cuestionó la prohibición de la técnica de fertilización in vitro, pues en el ordenamiento costarricense se pretendía dotar de una protección absoluta al embrión, aun cuando sí se permitía la técnica de inseminación artificial, la cual tampoco garantizaba que cada óvulo llegase a un embarazo, y que además implicaba, dentro de sus riesgos, una posible pérdida de embriones. Similar argumento fue aplicado, al establecerse una comparación con el embarazo natural, que tampoco aseguraba que un óvulo fecundado llegase a su término natural luego de un periodo de nueve meses.

\footnotetext{
CORTE IDH. Caso Artavia Murillo y otros vs. Costa Rica, párr. 314.

CORTE IDH. Caso Artavia Murillo y otros vs. Costa Rica, párr. 315.

CORTE IDH. Caso Artavia Murillo y otros vs. Costa Rica, párr. 316.
} 


\section{Conclusiones}

Desde comienzos del siglo XXI, el Sistema Interamericano de Derechos Humanos ha ido evolucionando en la tutela de nuevos derechos humanos, como los derechos de género, vinculados tanto a los derechos sexuales y reproductivos, como a los derechos a la orientación sexual e identidad. Lo cual se ha logrado gracias a otorgarle una vis expansiva a los clásicos derechos a la vida, integridad, libertad, igualdad y no discriminación, privacidad personal y familiar, entre otros artículos de la Convención Americana sobre Derechos Humanos.

Ello solo es posible gracias a los procesos modernización de las sociedades latinoamericanas, que en el marco de los procesos democráticos y constitucionales, desde el fin de las dictaduras militares y civiles de la región, vienen sentado las bases políticas y socio-culturales del pluralismo jurídico-político y la tolerancia social, como formas de gobierno y formas de vida.

No obstante, en América Latina el desarrollo de las democracias constitucionales no es un proceso lineal y ascendente, sino a veces contradictorio en la tutela de los derechos fundamentales y con recodos, como el alejamiento incluso del propio del SIDH o de la competencia contenciosa de la Corte IDH, de países que rechazan las sentencias condenatorias en materia de derechos a la vida, libertad de expresión, igualdad y no discriminacion e incluso debido proceso, como son los casos de los retiros de Venezuela y República Dominicana, o, como lo hizo antes Trinidad y Tobago y Perú con Fujimori, de la competencia contenciosa de la Corte Interamericana.

Pero, los problemas de los derechos humanos no se presentan únicamente en gobiernos con tendencias conservadoras o dictatoriales, donde se han producido graves o sistemáticas violaciones a los derechos humanos, sino también en gobiernos democráticos, que tienen los desafíos de asumir el pasivo de dichos regímenes, $y$, asumir los retos de la protección de los nuevos derechos humanos, como los derechos a la orientación sexual y de género, así como, como los derechos sexuales y reproductivos.

Por ello, es muy importante que en el caso Atala Riffo contra Chile, la Corte IDH haya incorporado la perspectiva de género en sus razonamientos. Por cuanto, ha establecido o definido contenidos o violaciones de derecho a partir del contraste con los estereotipos o roles tradicionales que se ha otorgado a la mujer. Así, la Corte IDH ha hecho referencia crítica a dichos roles en los que la mujer debe ser primero madre o esposa o cumplir un rol de reproducción sexual femenina, antes que elegir un proyecto de vida y de desarrollo personal y en consecuencia ejercer sus derechos a la identidad personal y/o definir su orientación sexual, entre otros.

La Corte IDH ha desvirtuado dichas categorías y ha realizado una interpretación de los derechos fundamentales orientada a eliminar los patrones históricos 
tradicionales que consideran a la mujer en una situación de desventaja frente al varón.

En otro sentido, también es relevante que la Corte IDH haya incorporado en su reflexión un concepto de familia en sentido amplio, en el que se privilegian los lazos y vínculos afectivos, antes que el modelo patriarcal de familia matrimonial propio de sociedades tradicionales pre modernas.

En el caso Artavia Murillo contra Costa Rica, es relevante que la Corte IDH haya incorporado conceptos como el de derecho a la discriminación indirecta, ya que ello refleja un análisis material del concepto de igualdad. En el mismo sentido, es importante que haya definido el concepto de los derechos sexuales y reproductivos sin discriminación particularmente indirecta, y, que haya diferenciado los tres supuestos: discapacidad, género y condiciones socioeconómicas, en los que se configura un trato desigual desproporcionado.

Asimismo, resulta relevante para la región que la Corte Interamericana haya definido el alcance de la protección jurídica de la vida desde la anidación, lo cual constituye en derecho internacional una sentencia con una "cosa interpretada", que tendrá consecuencias en las decisiones legislatvas o jurisrudenciales en debate en la Latinoamérica, por ejemplo, sobre el uso de la píldora del día siguiente, o, más aún sobre la despenalización del aborto.

De modo que, siendo tanto los derechos sexuales y reproductivos, como los derechos a la orientación sexual e identidad de género, asuntos que se presentan como problemas no solo jurídicos, sino sociales y hasta culturales, las decisiones que en adelante vaya asumiendo la Corte IDH, deberá tanto acompañar como impulsar los procesos legislativos y judiciales nacionales de tutela de nuevos derechos, sin perjuicio de los viejos derechos humanos.

Lima, 14 de febrero de 2015.

Recebido em: 12.11.2016.

Aprovado em: 13.12.2016.

\begin{abstract}
In the last decade, the Interamerican Court of Human Rights (ICHR) has stopped facing exclusively cases related to classical human rights in order to start ruling also on demands for brand new human rights relating to both sexual and reproductive rights, such as sexual orientation and gender identity.

The Court has undertaken an interpretation of fundamental rights oriented towards the elimination of historical traditional patterns that conceive of the woman in a situation of disadvantage vis-à-vis the husband. In addition, it is also noteworthy that the ICHR has incorporated in its reasoning a broad concept of family, one which takes into account emotional bonds and ties, in detriment of the patriarchal model of matrimonial family that is characteristic of traditional pre-modern societies.
\end{abstract}


The ICHR has incorporated concepts such as that of disparate impact, since it requires a material analysis of the concept of equality. It is also important that the Court has established the concept of sexual and reproductive rights without particularly indirect discrimination and that it has differentiated its three preconditions: incapacity, gender and economic status, in which case disproportionally unequal treatment accrues.

Keywords: Sexual rights. Reproductive rights. Interamerican Court of Human Rights.

Summary: 1 Presentation - 2 Sexual freedom: Atala Riffo and girls vs Chile - $\mathbf{3}$ Assisted sexual reproduction: Artavia Murillo and others vs Costa Rica $\mathbf{-} \mathbf{4}$ Conclusions

Resumo: A Corte Interamericana de Direitos Humanos (CIDH) deixou de enfrentar, na última década, exclusivamente casos vinculados a direitos humanos clássicos para começar a decidir também sobre demandas por novíssimos direitos humanos relativos tanto aos direitos sexuais e reprodutivos, quanto à orientação sexual e identidade de gênero. A Corte realizou a interpretação dos direitos fundamentais orientada a eliminar os padrões históricos tradicionais que consideram a mulher em uma situação de desvantagem frente ao marido. Em outro sentido, também é relevante que a CIDH tenha incorporado em sua reflexão o conceito de família no sentido amplo, no qual se privilegiam os laços e vínculos afetivos, em detrimento do modelo patriarcal de família matrimonial próprio de sociedades tradicionais pré-modernas. A CIDH incorporou conceitos como o da discriminação indireta, já que ela reflete uma análise material do conceito de igualdade. No mesmo sentido, é importante que tenha definido o conceito dos direitos sexuais e reprodutivos sem discriminação particularmente indireta e que tenha diferenciado os três pressupostos: incapacidade, gênero e condições socioeconômicas, nos quais se configura um tratamento desigual desproporcional.

Palavras-chave: Direitos sexuais. Direitos reprodutivos. Corte Interamericana de Direitos Humanos.

Sumário: 1 Apresentação - $\mathbf{2}$ Liberdade sexual: Atala Riffo e meninas vs. Chile - $\mathbf{3}$ Reprodução sexual assistida: Artavia Murillo e outros vs. Costa Rica $\mathbf{-} \mathbf{4}$ Conclusões

\section{Bibliografia consultada}

BENDA, Ernst (1996): Manual de Derecho Constitucional. Madrid, Marcial Pons.

BERNAL PULIDO, Carlos (s/fecha): “El juicio de la igualdad en la jurisprudencia de la Corte Constitucional Colombiana". Universidad Externado de Colombia. Disponible en línea: http:// portal.uexternado.edu.co/pdf/2_icrp/elJuicioDeLalgualdadEnLaJurisprudencia.pdf [03 de febrero de 2015].

BRENA, Ingrid (2013): “Comentarios a la Sentencia de la Corte Interamericana de Derechos Humanos. Caso Artavia Murilo y otros (Fecundación in vitro) vs. Costa Rica", Boletín Mexicano de Derecho Comparado. Nueva serie, año XLVI, No. 137, UNAM, Instituto de Investigaciones Jurídicas. Disponible en línea: http://biblio.juridicas.unam.mx/revista/pdf/ DerechoComparado/137/inf/inf13.pdf [03 de febrero de 2015].

CANOSA, Raúl (2006): El derecho a la integridad personal. Madrid, Lex Nova.

CENTRO DE DERECHOS REPRODUCTIVOS (s/fecha): "Objeción de conciencia y derechos reproductivos. Estándares Internacionales de Derechos Humanos". Disponible en línea: http://reproductiverights.org/sites/crr.civicactions.net/files/documents/CRR_LAC_ ConcientiousObjectionFactSheets_10_17_13.pdf [03 de febrero de 2015]. 
COMISIÓN INTERAMERICANA DE DERECHOS HUMANOS (2011): “Acceso a la información en materia reproductiva desde una perspectiva de derechos humanos". Disponible en línea: https://www.oas.org/es/cidh/mujeres/docs/pdf/ACCESO\%2OINFORMACION\%20 MUJERES. pdf [03 de febrero de 2015].

DELGADO SCHNEIDER, Verónica Pía (s/fecha): “El principio de la protección legal de la vida y la salud del nasciturus y la acción popular en el modelo de Andrés Bello (Códigos Civiles de Chile, Ecuador, El Salvador, Colombia, Panamá, Honduras y Nicaragua)", Revista Derecho Privado. Disponible en línea: http://portal.uexternado.edu.co/pdf/revistaDerecho Privado/ rdp12-13/veronicaPiaDelgado.pdf [03 de febrero de 2015].

DÍAZ REVORIO, Francisco Javier (2009): Los derechos humanos ante los nuevos avances científicos y tecnológicos. Genética e internet ante la Constitución. Valencia: Tirant lo Blanch.

DIEZ-PICAZO, Luis (2005): Sistema de derechos fundamentales. Madrid, Civitas.

GIL DOMINGUEZ, Andrés, María Victoria FAMÁ, Marisa HERRERA (2012): Derecho Constitucional de Familia. Tomo I. Buenos Aires, Ediar.

LANDA, César (2002): “Dignidad de la persona humana”, Cuestiones Constitucionales 7. Revista Mexicana de Derecho Constitucional.

LANDA, César (2009): “Dignidad”, Diccionario de Derechos Humanos. Universidad de Alcalá. Disponible en línea: http://diccionario.pradpi.org/inicio/index.php/terminos_pub/to_pdf/59 [03 de febrero de 2015].

ORGANIZACIÓN DE LAS NACIONES UNIDAS (1994): “Informe de la Conferencia Internacional sobre la Población y el Desarrollo". El Cairo. Disponible en línea: http://www.unfpa.org/ sites/default/files/event-pdf/icpd_spa_2.pdf [03 de febrero de 2015].

ORGANIZACIÓN MUNDIAL DE LA SALUD (2013): “Salud mental: un estado de bienestar”. Disponible en línea: http://www.who.int/features/factfiles/mental_health/es/ [03 de febrero de 2015].

PAUTASSI, Laura (2012): “La igualdad en espera: El enfoque de género". En ALEGRE, Marcelo y Roberto GARGARELLA (Coordinadores). El derecho a la igualdad. Aportes para un constitucionalismo igualitario.Buenos Aires: Abeledo Perrot, pp. 715-735.

PIOVESAN, Flavia (s/fecha): “Prohibición de la discriminación por orientación sexual en los sistemas regionales: la sentencia de la corte interamericana de derechos humanos en el caso Atala Riffo vs. Chile", Anuario de Derecho Público. FRASER, Nancy. "Social Justice in the Age of Identity Politics: Redistribution, Recognition, and Participation". Consulta realizada el 14 de febrero de 2015. Disponible en línea: http://tannerlectures. utah.edu/_documents/ato-z/f/Fraser98.pdf [03 de febrero de 2015].

RAMÍREZ HUAROTO, Beatriz (s/fecha). En: “Los derechos reproductivos en la jurisprudencia de la Corte Interamericana de Derechos Humanos: apuntes sobre la sentencia en el caso Artavia Murillo y otros contra Costa Rica". En: Práctica Constitucional. Actualidad Constitucional; p. 366. Disponible en línea: http://www.academia.edu/4127932/ Beatriz_Ramirez_-_Los_derechos_reproductivos_en_la_jurisprudencia_de_la_Corte_ Interamericana_de_Derechos_Humanos_apuntes_sobre_la_sentencia_en_el_caso_Artavia_ Murillo_y_otros_contra_Costa_Rica [03 de febrero de 2015]. 
REY, Fernando (2011): “Igualdad”. En: Diccionario de Derechos Humanos. Universidad de Alcalá. Consulta realizada el 3 de febrero de 2015. Disponible en línea: http://diccionario. pradpi.org/inicio/index.php/terminos_pub/view/78 [03 de febrero de 2015].

SPASIUK, Gisela Elizabeth y Zulma CABRERA (2009): “Alcances, posibilidades y límites de la protección de derechos reproductivos en Misiones: el caso del Programa de Salud Sexual y Reproductiva. Segundo Encuentro del Observatorio de Género y Pobreza". Disponible en línea: http://www.generoypobreza.org.ar/archivo-doc/ item/205-alcances-posibilidades-y-l\%C3\%ADmites-de-la-protecci\%C3\%B3n-de-derechosreproductivos-en-misiones-el-caso-del-programa-de-salud-sexual-y-reproductiva (descarga) [03 de febrero de 2015].

VILLAVICENCIO TERREROS, Felipe (s/fecha): "Protección al derecho a la vida". Disponible en línea: http://www.derecho.usmp.edu.pe/sapere/sumario/edicion_2/articulos/Proteccion_del _derecho_a_la_vida.pdf [03 de febrero de 2015].

\section{Jurisprudencia y legislación consultada}

CORTE IDH. Caso Artavia Murillo y otros vs. Costa Rica. Excepciones preliminares, fondo, reparaciones y costas. Sentencia del 28 de noviembre de 2012. Serie C No. 257.

CORTE IDH. Caso Artavia Murillo y otros vs. Costa Rica. Resumen oficial emitido por la Corte Interamericana de la Sentencia de 28 de noviembre de 2012. Excepciones preliminares, fondo, reparaciones y costas. Disponible en web: http://www.corteidh.or.cr/docs/casos/ articulos/resumen_257_esp.pdf [03 de febrero de 2015].

CORTE IDH. Caso Atala Riffo y Niñas Vs. Chile. Fondo, Reparaciones y Costas. Sentencia del 24 de febrero de 2012. Serie C No. 239.

CORTE IDH. Caso de las Masacres de Ituango Vs. Colombia. Excepción Preliminar, Fondo, Reparaciones y Costas. Sentencia de 1 de julio de 2006. Serie C No. 148.

CORTE IDH. Caso La Cantuta vs. Perú. Interpretación de la Sentencia de Fondo, Reparaciones y Costas). Sentencia del 30 de noviembre de 2007. Serie C No. 173.

TRIBUNAL CONSTITUCIONAL DEL PERÚ. Expediente 02273-2005-PHC/TC.

TRIBUNAL CONSTITUCIONAL DEL PERÚ. Sentencia 02005-2009-PA/TC.

Informação bibliográfica deste texto, conforme a NBR 6023:2002 da Associação Brasileira de Normas Técnicas (ABNT):

LANDA, César. Los derechos sexuales y reproductivos en la jurisprudencia de la Corte Interamericana de Derechos Humanos. Direitos Fundamentais \& Justiça, Belo Horizonte, ano 10, n. 35, p. 47-78, jul./dez. 2016. 